\title{
Impact of minerals and water on bitumen-mineral adhesion and debonding behaviours using molecular dynamics simulations ${ }^{1}$
}

\author{
Yangming Gao, PhD student \\ Aston Institute of Materials Research, and Engineering System \& Management Group \\ School of Engineering and Applied Science \\ Aston University \\ Aston Triangle, Birmingham, B4 7ET, U.K. \\ Email: gaoy14@aston.ac.uk \\ Yuqing Zhang, PhD. \\ Lecturer in highway engineering \\ Aston Institute of Materials Research, and Engineering System \& Management Group \\ School of Engineering and Applied Science \\ Aston University \\ Aston Triangle, Birmingham, B4 7ET, U.K. \\ Phone: +44 121-204-3391, Email: y.zhang10@aston.ac.uk \\ (Corresponding author)
}

Fan Gu, PhD.

Marie Curie Research Fellow

Aston Institute of Materials Research

Aston University

Aston Triangle, Birmingham, B4 7ET, U.K.

Email: f.gu1@aston.ac.uk

Tao Xu, PhD.

Professor,

School of Civil Engineering,

Nanjing Forestry University

Nanjing 210037, Jiangsu, China

Email: seuxt@163.com

Hao Wang, PhD.

Associate Professor,

Department of Civil \& Environmental Engineering

School of Engineering

Rutgers, The State University of New Jersey

96 Frelinghuysen Road, Piscataway, NJ 08854

Email: hwang.cee@rutgers.edu

\footnotetext{
${ }^{1}$ This is an Accepted Manuscript of an article published by journal of Construction and Building Materials. The full text is available at:

https://doi.org/10.1016/j.conbuildmat.2018.03.136
} 


\section{ABSTRACT}

This study aims to evaluate the effects of mineral types and water on the adhesion properties and debonding behaviours of bitumen-mineral interface systems. A molecular dynamics modelling approach was employed to simulate the interactions between minerals and bitumen with and without the presence of water. Four representative minerals (quartz, calcite, albite and microcline) were selected to build the mineral-bitumen interface systems and the mineralwater-bitumen interface systems in the molecular dynamics models. The adhesion property between minerals and bitumen was quantified by work of adhesion, defined as the energy required to separate a unit area of the bitumen-mineral interface. The debonding behaviour between minerals and bitumen is characterised by work of debonding, defined as the energy required to displace bitumen by water at the mineral-bitumen interface. The simulation results were validated by available experimental results reported in the literature. It was found that the work of adhesion and the work of debonding for the four bitumen-minerals interface systems are ranked microcline $>$ albite $>$ calcite $>$ quartz at both dry and wet conditions. Moisture can reduce the adhesion between minerals and bitumen by $82 \%, 84 \%, 18 \%$ and $1 \%$ for the quartz, calcite, albite and microcline, respectively. The adhesion between minerals and bitumen is attributed to the non-bond interaction energy, in which the major component is van der Waals interaction for neutral minerals (e.g., quartz) and the electrostatic interaction for the alkali minerals (e.g., calcite, albite and microcline). The bitumen-mineral debonding is a thermodynamically favourable process with reduced total potential energy of the system. It is concluded that the bitumen-mineral adhesion and debonding behaviours strongly depends on the chemistry and mineralogical properties of the minerals. This work provides a fundamental understanding of the adhesion and debonding behaviours of the bitumen-mineral interface at the atomistic scale.

\section{KEYWORDS}

Aggregate minerals; bitumen-mineral interface; adhesion; debonding; stripping mechanism; molecular dynamics 


\section{Introduction}

Asphalt pavements are subjected to heavy and repeated traffic loading, leading to severe cracks and moisture damages when water exist in the pavement structures. Zhang and Lytton et al. investigated the crack initiation and evolution in asphalt mixtures under compressive and tensile loads [1-2]. They found that the bond energy of an asphalt mixture dominated the crack initiation and propagation processes and it increases with aging period and loading rate and decreases with temperature [3-4]. Previous studies have reported that the mechanical properties of asphalt mixtures had a strong dependency upon the interfacial bond between bitumen and aggregate [5-6]. Therefore, the adhesion of the bitumen-aggregate interface needs to be strong and durable under the complex traffic and environment conditions. Fundamentally this is caused by that water diffuses into asphalt layer of the pavements and weakens the bitumen-aggregate adhesive bond in asphalt mixtures. Stripping happens when the adhesive debonding occurs between bitumen and aggregate. In order to understand the stripping mechanism of asphalt mixtures and extend the pavement service life, there is a fundamental need to investigate the adhesion properties and moisture damage mechanisms of the bitumenaggregate interface.

Researchers have developed experimental testing methods to investigate the mechanism of adhesion between bitumen and aggregate with and without moisture effect. Lytton et al. [7] measured surface energy components of bitumen and aggregate and derived the adhesive bond strength between aggregate and bitumen to quantify the moisture susceptibility of the asphalt mixture. Khattak et al. [8] performed the lap-shear test to study binder-aggregate adhesion at low temperature. Canestrari et al. [9] used the Pneumatic Adhesion Tensile Testing Instrument (PATTI) to evaluate the influence of water on cohesive and adhesive properties of bitumenaggregate systems. Moraes et al. [10] investigated the feasibility of the Bitumen Bond Strength (BBS) test for moisture damage characterization of the bitumen-aggregate interface. Fini and Al-Qadi [11] developed a pressurized blister test to characterize the interfacial adhesion between aggregate and bituminous materials. Fischer et al. [12] employed atomic force microscopy (AFM) to investigate the interfacial interaction between bitumen and the minerals as present in asphalt mixtures. These experimental studies provided a good understanding of bitumen-aggregate adhesion and moisture susceptibility of the asphalt mixtures.

Recently, with the development of the high-performance computation, atomistic and molecular modelling has become an effective way to interpret the material properties or system behaviours from fundamental molecular processes. Researchers employed molecular dynamic (MD) simulation to investigate the molecular interaction and basic properties of bitumen and the mechanical behaviours of asphalt concrete. Zhang and Greenfield [13-14] and Li and 
Gao, et al.

Greenfield [15-16] developed the model bitumen systems to represent the real bitumen and analysed the physical properties of the model bitumen (e.g. viscosity, relaxation time, diffusion coefficient, and dynamics) using molecular simulation. Lu and Wang [17-18], Wang et al. [19], and $\mathrm{Xu}$ and Wang [20] performed MD simulation to evaluate the mechanical properties of the bitumen-aggregate interface. MD simulation has also been applied to investigate the oxidative aging behaviours [21-23], diffusion and self-healing mechanisms [24-26], and micromechanical properties of bitumen [27-29]. These research efforts have produced important results for better understanding the physical, rheological, and thermodynamic properties of the real bitumen from a more fundamental perspective.

However, most of the research effort was spent on the effect of the bitumen or bitumen compositions on the adhesion, whereas little work has been focused on the effect of aggregate mineral compositions on the adhesion and debonding behaviours between aggregate and bitumen at the atomistic scale. Some experimental studies have shown that the chemical and mineralogical compositions of the aggregate minerals significantly affect the stripping properties of asphalt mixtures. Lyne et al. [29] reported that the elemental composition of a mineral affected its dispersive adhesion to bitumen. Horgnies et al. [30] presented that the adhesion of the bitumen on micas and quartz was better than the one on alkali feldspars. More fundamental studies by atomistic modelling are needed to reveal the mechanisms of the debonding between aggregate minerals and bitumen when different mineral compositions are present.

The objective of this study is to investigate the effects of aggregate mineral types on the adhesion property and debonding behaviour of the bitumen-mineral interface with and without the presence of water using an atomistic modelling approach. The molecular models of four representative minerals were employed to construct the mineral-bitumen and mineral-waterbitumen interface systems. The interface molecular interactions were quantified using the molecular dynamics (MD) simulations. The adhesion and debonding properties of the bitumenmineral interface were evaluated using the work of adhesion and the work of debonding. Furthermore, the wet interface stripping mechanism was analysed through investigating the mineral-bitumen debonding process at the atomistic scale.

\section{Aggregate minerals}

Aggregates used in pavement structure are mineral rocks. The composition of the aggregates, based on chemistry and mineralogy, are quite complex and have diverse mineralogical composition. Some aggregates mainly contain one mineral such as quartzite $\left(\mathrm{SiO}_{2}\right)$ and limestone $\left(\mathrm{CaCO}_{3}\right)$. Other aggregate types are composed of several different minerals. For 
example, the major minerals in granite are quartz, mica and feldspar.

A mineral is an element or chemical compound that is normally crystalline and has been formed as a result of geological processes [31]. The eight most common elements of the minerals in the earth's crust are oxygen, silicon, aluminium, iron, calcium, sodium, potassium and magnesium [32]. Natural rock mineral is polycrystal with local periodicity. A crystal structure is based on the orderly internal atomic or ionic arrangement. The structure of a mineral in the geometric form is often expressed by a box with parallel sides called the unit cell. The box with periodicity in all three dimensions is defined by six lattice parameters (lengths a, b, c, and angles $\alpha, \beta, \gamma)$. The crystal structure greatly affects a mineral's physical properties, and it together with the mineral chemical composition defines a mineral. Therefore, a mineral has a characteristic chemical composition and a regular atomic structure, leading to specific physical properties.

In this study, four representative minerals (quartz, calcite, albite, and microcline) were selected to investigate their debonding behaviour with bitumen using MD simulation. These four minerals were selected based on that 1 ) they are the common minerals existing in the aggregates that are used for constructing asphalt mixtures and 2) the four minerals have been comprehensively measured for their surface energy in the literature by Little and Bhasin [33].

\section{Simulation models and methods}

\subsection{Molecular dynamics simulation}

Molecular dynamics (MD) is a computational modelling technique for analysing the fundamental material properties such as density, modulus, viscosity, diffusion and surface energy and the material performance such as deformation and debonding at nanoscale through simulating the material atomistic movements and interactions. The principles of MD simulation are statistical mechanics and Newton's law of motions. MD is used to calculate the thermodynamic performance of a material system, in which the motion of each atom obeys Newton's law of motions.

The essential input to the MD simulation is an interatomic potential which defines the forces between atoms and is characterised by force field. A number of force fields have been developed by researchers for different materials [34]. An appropriate force field should be able to mimic the nature of atomic interaction in a material system. The Condensed-phase Optimized Molecular Potentials for Atomistic Simulation Studies (COMPASS) force field is the first $a b$ initio force field that can effectively consolidate the atomic parameters of organic and inorganic materials. It has been successfully applied for simulating the bitumen-aggregate interface in a previous study [35]. Thus the COMPASS force field is selected for this study and described as 
[36]:

$$
\begin{gathered}
E_{\text {total }}=E_{\text {val }}+E_{\text {non-bond }} \\
E_{\text {val }}=E_{\mathrm{b}}+E_{\theta}+E_{\varphi}+E_{\chi}+E_{\mathrm{bb}},+E_{\mathrm{b} \theta}+E_{\mathrm{b} \varphi}+E_{\theta \varphi}+E_{\theta \theta^{\prime}}+E_{\theta \theta^{\prime} \varphi} \\
E_{\text {non-bond }}=E_{\text {elec }}+E_{\mathrm{LJ}}
\end{gathered}
$$

The total potential energy ( $\left.E_{\text {total }}\right)$ consists of valence and non-bond interaction terms. The valence term $\left(E_{\mathrm{val}}\right)$ include the interactions of bond stretching $\left(E_{\mathrm{b}}\right)$, angle bending $\left(E_{\theta}\right)$, internal torsion $\left(E_{\varphi}\right)$, out-of-plane bending $\left(E_{\chi}\right)$ and the cross-coupling terms ( $E_{\mathrm{bb}}, E_{\mathrm{b} \theta}, E_{\mathrm{b} \varphi}, E_{\theta \varphi}, E_{\theta \theta}$, and $\left.E_{\theta \theta^{\prime} \varphi}\right)$. The non-bond interaction term ( $\left.E_{\text {non-bond }}\right)$ quantifies the non-covalent contributions including Coulomb electrostatic energy ( $\left.E_{\text {elec }}\right)$ and the van der Waals energy $\left(E_{\mathrm{LJ}}\right)$.

MD simulations were performed using Materials Studio [37] with the COMPASS force field. In the simulation, the mineral-bitumen interface model consists of aggregate mineral and bitumen layers. The component of the aggregate mineral is the crystal with a periodic crystalline structure, while the bitumen is an amorphous material model. In order to successfully simulate the interface system, it is critical to construct reasonable atomistic models representing the real aggregate mineral and bitumen. The following sections explain how the atomistic models for minerals, bitumen and mineral-bitumen interface are built in the MD simulations.

\subsection{Molecular model of minerals}

Quartz, calcite, albite and microcline are selected as the minerals in this simulation. The unit cell structures and lattice parameters of these four minerals are summarized in Table $\mathbf{1}$. To model the mineral substrate, the bulk crystal was first cleaved along $[1,0,0]$ direction to expose the corresponding surface. After geometry transformation, the crystal surface was extended to generate a two-dimension (2D) structure by repeating the unit cell in $\mathrm{x}$ and $\mathrm{y}$ directions. Then a vacuum slab was included above this extended surface to create a mineral block called a supercell with three-dimension (3D) periodic boundary conditions. Fig. 1 shows the final mineral model used for the simulation (use microcline as an example).

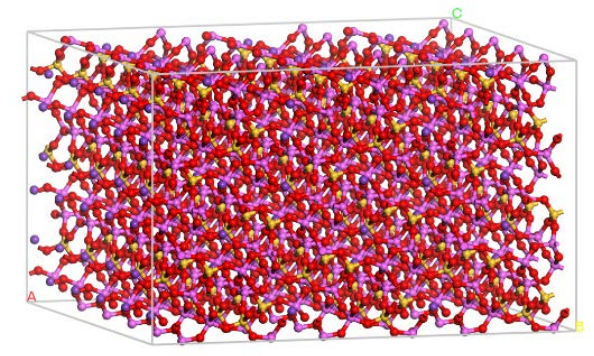


Fig. 1. An atomistic model of microcline substrate used for the simulation.

\subsection{Bitumen molecular model}

Bitumen has a quite complex chemical composition. It contains a high percentage of hydrocarbons with a few structurally analogous heterocyclic species and functional groups including oxygen, sulphur and nitrogen atoms. Research efforts have been made to construct bitumen model with reasonable chemical composition. American Society for Testing and Materials (ASTM) D4124-09 proposed SARA (saturate, aromatic, resin and asphaltene) classification system. To better understand the physical, rheological and mechanical properties of the bitumen, three 12-component model bitumen systems were developed by $\mathrm{Li}$ and Greenfield [15] to represent the AAA-1, AAK-1, and AAM-1 bitumen, which were validated by experimental values from Jones [38]. The 12-component AAA-1 bitumen model was employed in this study, and the bitumen model compositions are listed in Table 2. The bitumen model contains two types of saturates (S), two types of aromatics (A), five types of resins (R), and three types of asphaltenes (A).

A bulk bitumen model was first constructed using amorphous cell module in Materials Studio. The molecules of the twelve components in the AAA-1 bitumen model were filled into a cubic box with an initial density of $0.1 \mathrm{~g} / \mathrm{cm}^{3}$ in $3 \mathrm{D}$ periodical condition on the basis of the assigned weight proportions of each constituent shown in Table 2. After a geometry optimization process, the MD simulation with the isothermal-isobaric (NPT) ensemble was conducted for 100 ps with a time step of $1 \mathrm{fs}$ to reduce the system volume. Then this configuration was further equilibrated in the constant volume and temperature (NVT) ensemble for another $100 \mathrm{ps}$ to approach a stable state. The target density can be obtained from the last frame of the simulation.

Table 1 The details of four minerals used in MD simulation.

\begin{tabular}{llll}
\hline Minerals & Unit cell structure & Lattice parameters & Chemical formula \\
\hline Quartz & $\mathrm{a}=\mathrm{b}=4.910 \AA \mathrm{A}, \mathrm{c}=5.402 \AA$ & $\mathrm{SiO}_{2}$ \\
& $\alpha=\beta=90, \gamma=120$ &
\end{tabular}


Gao, et al.

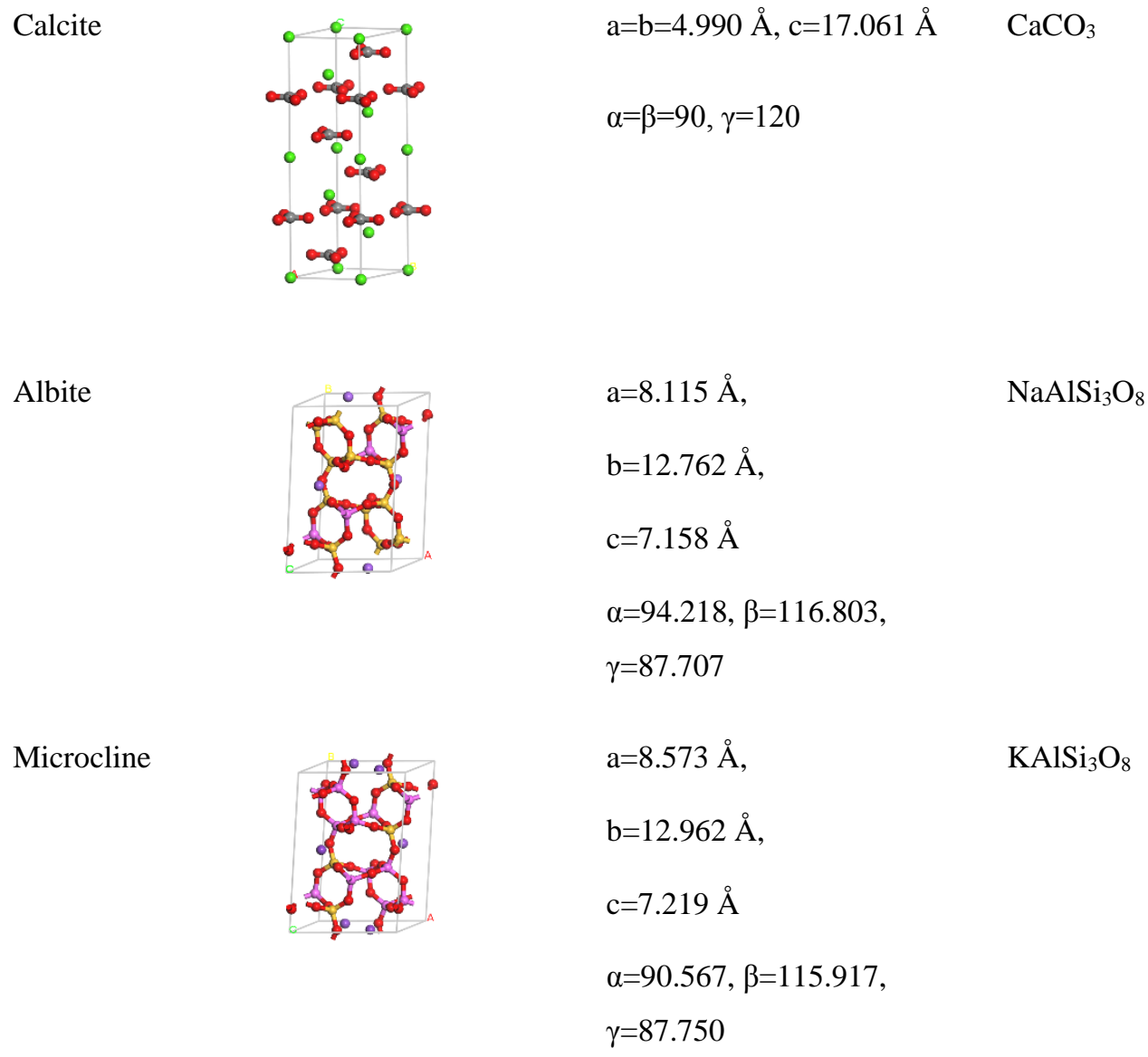

Table 2 Compositions of the employed bitumen molecular model for MD simulations [15].

\begin{tabular}{llllrr}
\hline Label & Molecules in model & $\begin{array}{l}\text { Molecular } \\
\text { formula }\end{array}$ & $\begin{array}{l}\text { Number of } \\
\text { molecules }\end{array}$ & $\begin{array}{l}\text { Mass } \\
\text { fraction (\%) }\end{array}$ \\
\hline SA-1 & Saturate & Squalane & $\mathrm{C}_{30} \mathrm{H}_{62}$ & 4 & 5.35 \\
SA-2 & & Hopane & $\mathrm{C}_{29} \mathrm{H}_{50}$ & 4 & 5.05 \\
AR-1 & Aromatic & PHPN & $\mathrm{C}_{35} \mathrm{H}_{44}$ & 11 & 16.19 \\
AR-2 & (Naphthene & DOCHN & $\mathrm{C}_{30} \mathrm{H}_{46}$ & 13 & 16.74 \\
& aromatic) & & & & \\
RE-1 & Resin & Quinolinohopane & $\mathrm{C}_{34} \mathrm{H}_{47} \mathrm{~N}$ & 4 & 5.95 \\
RE-2 & (Polar & Thioisorenieratane & $\mathrm{C}_{40} \mathrm{H}_{60} \mathrm{~S}$ & 4 & 7.26 \\
RE-3 & aromatic) & Benzobisbenzothiophene & $\mathrm{C}_{18} \mathrm{H}_{10} \mathrm{~S}_{2}$ & 15 & 13.80 \\
RE-4 & & Pyridinohopane & $\mathrm{C}_{30} \mathrm{H}_{45} \mathrm{~N}$ & 4 & 5.32 \\
RE-5 & & Trimethybenzeneoxane & $\mathrm{C}_{29} \mathrm{H}_{50} \mathrm{O}$ & 5 & 6.57 \\
AS-1 & Asphaltene & Asphaltene-phenol & $\mathrm{C}_{42} \mathrm{H}_{50} \mathrm{O}$ & 3 & 5.42 \\
AS-2 & & Asphaltene-pyrrole & $\mathrm{C}_{66} \mathrm{H}_{81} \mathrm{~N}$ & 2 & 5.63 \\
AS-3 & & Asphaltene-thiophene & $\mathrm{C}_{51} \mathrm{H}_{62} \mathrm{~S}$ & 3 & 6.72 \\
\hline
\end{tabular}


Gao, et al.

A confined bitumen layer with the target density was created using amorphous cell tool in order for the mineral-bitumen interface modelling in Section 3.4. The width and length of the confined bitumen layer was constructed to match with that of the mineral substrate created in Section 3.2. The bitumen layer model first ran a geometry optimization to minimize system energy, and the MD simulation with NVT ensemble was then performed for $100 \mathrm{ps}$ to generate an equilibrated model. The confined bitumen layer in the z-direction was non-periodic and had a flat surface, which was different from the bulk bitumen model that was periodic in z-direction.

\subsection{Molecular model of the mineral-bitumen interface}

The mineral-bitumen interface system was constructed by attaching the confined bitumen layer to the mineral substrate. A vacuum layer of $30 \AA$ was then added to the top open surface of this confined bitumen layer. The interface models are illustrated in Fig. 2 (a) where a microcline mineral was used as an example.

Based on the interface model, the moisture effect was studied by adding water molecules at the mineral-bitumen interface. A thin confined layer of 200 water molecules was placed between mineral and bitumen layers to construct a mineral-water-bitumen model, as shown in Fig. 2 (b) (use the microcline mineral as an example). The mineral-water-bitumen model assumed that water interrupted the mineral-bitumen interface and caused the debonding between mineral and bitumen, which was considered as the major mechanism of the moisture-induced damage (stripping) in asphaltic mixtures [39-40].

In the MD simulations, the interface models with or without water molecules were first subjected to a geometry optimization, and then a dynamic equilibration run of 100 ps with NVT ensemble was carried out to further optimize the model configuration. In this study, all MD simulations were conducted at $298 \mathrm{~K}$ with a time step of $1 \mathrm{fs}$ and the cut-off distance for atomistic interactions was $15.5 \AA$. These parameters have been proved to be appropriate for simulating the asphalt materials [23]. 


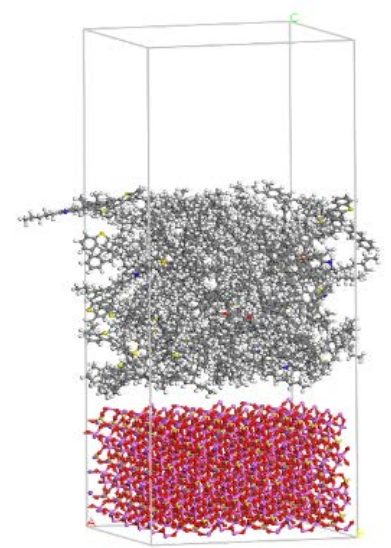

(a)

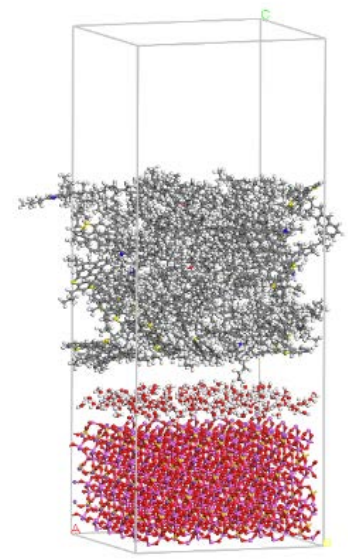

(b)

Fig. 2. Molecular interaction models for (a) the microcline-bitumen interface system and (b) microcline-water-bitumen interface system.

\section{Results and discussion}

\subsection{Simulation results of molecular dynamics modelling}

The structures of mineral-bitumen interface for the four selected minerals after the MD simulations (namely, geometry optimization and dynamic equilibration) are shown in Fig. 3. The adhesive interactions between the minerals and bitumen can be intuitively observed based on the distance between minerals and bitumen which reflects the interfacial bonding strength between the two materials. A smaller distance between the two materials indicates a higher atomic interacting force and therefore a higher bonding strength for the mineral-bitumen system. This is due to the fact that the mineral-bitumen interactions are dominated by the non-bond terms including Coulomb electrostatic and van der Waals forces. They both are associated with the distance between atoms, which means that a smaller atomic separation distance leads to a higher atomic force. Thus, from Fig. 3, it can be found that the adhesion of microcline with bitumen is the strongest among the four minerals while quartz with bitumen has the weakest adhesion. 


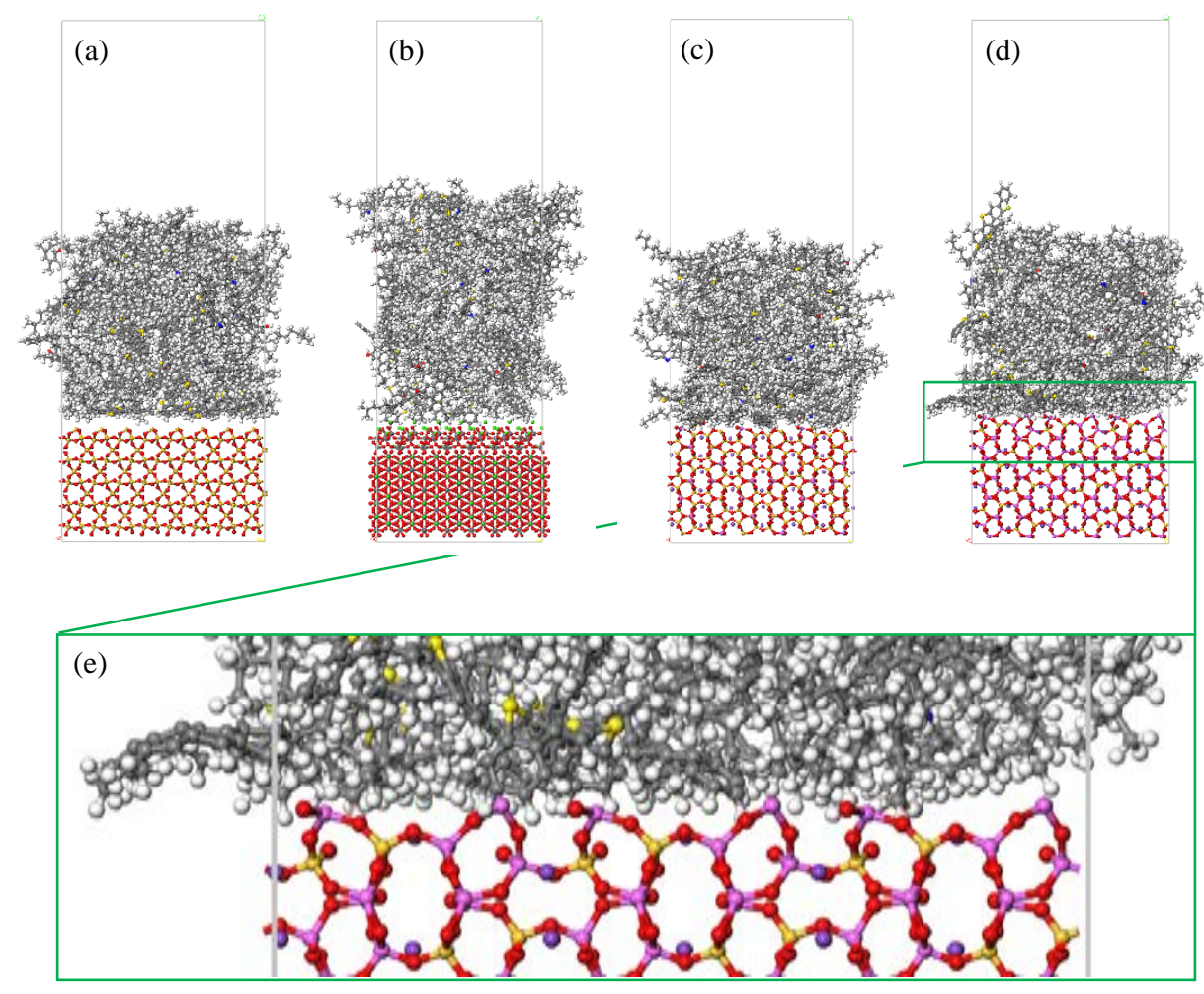

Fig. 3. Mineral-bitumen interface systems after MD simulations: (a) quartz-bitumen model; (b) calcitebitumen model; (c) albite-bitumen model; (d) microcline-bitumen model; and (e) locally enlarged interface structure for microcline-bitumen model.

Fig. 4 shows the structures of mineral-water-bitumen interface systems for the four selected minerals after MD simulations. It can be observed that an obvious gap exists between the quartz or calcite and the bitumen molecules in the presence of water. This results from the degraded adhesion and debonding between quartz or calcite and bitumen when water diffuses into the interface. In comparison the albite-water-bitumen and microcline-water-bitumen models did not show any obvious gaps, indicating a strong adhesion between the minerals and bitumen. Thus, it can conclude that the adhesion of albite and microcline with bitumen is stronger than those of quartz and calcite with bitumen under wet condition. This observation will be quantitatively validated by the work of adhesion determined from the MD simulation in Section

\section{2.}

Fig. 4 also shows that the water molecules in the quartz-water-bitumen model are interspersed in the gap between quartz and bitumen, while for the calcite-water-bitumen model, the water molecules have moved more closely to the calcite mineral surface. This may result from that the quartz has a symmetric molecular structure and exhibits very neutral and weak adhesion force with water molecules. In contrast, the calcite has an unsymmetrical molecular structure with calcium ions, leading to a higher secondary atomic bond and a relatively higher adhesion 
force with water molecules.
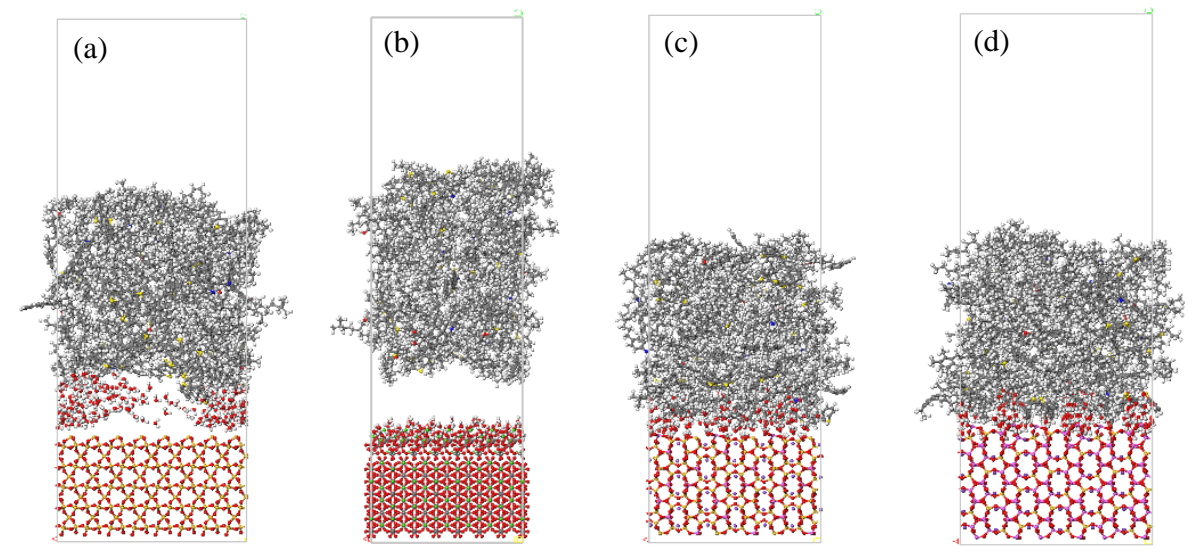

Fig. 4. Mineral-water-bitumen interface systems after MD simulations: (a) quartz-water-bitumen model; (b) calcite-water-bitumen model; (c) albite-water-bitumen model; and (d) microcline-water-bitumen model.

\subsection{Adhesion between minerals and bitumen at dry and wet conditions}

In order to quantify the adhesion between minerals and bitumen, the work of adhesion of mineral-bitumen system is calculated in this study. The work of adhesion is defined as the energy required to separate a unit area of an interface into two free surfaces in a vacuum [33]. It reflects the bonding strength of the mineral-bitumen interface. The work of adhesion $\left(W_{\mathrm{MB}}\right)$ is defined by Eq. (4) using an interaction energy $\left(\Delta E_{\mathrm{MB}}\right)$ which is derived from Eq. (5) [33] [41]. Note that the parameters in Eqs. (4) and (5) are calculated based on the MD simulation results of the mineral-bitumen models and the mineral-water-bitumen models to obtain the work of adhesion in dry and wet conditions, respectively.

$$
\begin{gathered}
W_{\mathrm{MB}}=\Delta E_{\mathrm{MB}} / A \\
\Delta E_{\mathrm{MB}}=E_{\mathrm{M}}+E_{\mathrm{B}}-E_{\mathrm{MB}}
\end{gathered}
$$

where $W_{\mathrm{MB}}$ is the work of adhesion between a mineral and bitumen; $\Delta E_{\mathrm{MB}}$ is the interaction energy between the mineral and bitumen; $E_{\mathrm{M}}$ and $E_{\mathrm{B}}$ are the potential energies of the mineral and bitumen at a thermodynamic equilibrium, respectively; $E_{\mathrm{MB}}$ is the total potential energy of mineral-bitumen system at the thermodynamic equilibrium; and $A$ is the contact area of the interface between mineral and bitumen calculated using the Connolly area of mineral surface. The Connolly area can reflect the morphological feature of mineral and bitumen and thus more reasonably describe the interface contact area [41]. 
Gao, et al.

Table 3 lists the calculated interaction energy $\left(\Delta E_{\mathrm{MB}}\right)$ and the work of adhesion $\left(W_{\mathrm{MB}}\right)$ between minerals and bitumen at dry and wet conditions. At dry condition, the work of adhesion ( $W_{\mathrm{MB}-}$ dry $)$ for the quartz-bitumen bond is $42.87 \mathrm{~mJ} / \mathrm{m}^{2}$, while the work of adhesion ( $W_{\text {MB-dry }}$ ) of the calcite-bitumen bond is $57.13 \mathrm{~mJ} / \mathrm{m}^{2}$. Thus, the work of adhesion ( $\left.W_{\text {MB-dry }}\right)$ between calcite and bitumen is greater than that between quartz and bitumen, which means the calcite-bitumen bond is stronger than the quartz-bitumen bond under dry condition. This agrees well with the laboratory measurements finding that limestone (in which calcite is the major component) shows larger adhesion strength with bitumen than granite with quartz as its main component [42]. The ranking for the adhesion between the four minerals with bitumen is as follows: microcline $>$ albite $>$ calcite $>$ quartz, as shown in Table 3 . This indicates that mineral type has a significant impact on the adhesion between minerals and bitumen. Furthermore, it is noted that the work of adhesion ( $\left.W_{\text {MB-dry }}\right)$ for the microcline-bitumen bond $\left(3241.55 \mathrm{~mJ} / \mathrm{m}^{2}\right)$ and the albite-bitumen bond $\left(1257.25 \mathrm{~mJ} / \mathrm{m}^{2}\right)$ is much higher than that for the quartz-bitumen bond and the calcite-bitumen bond. This is because microcline and albite are strongly alkaline minerals with highly positive electronic charges. This finding verifies the existing experimental results that a mineral with an alkaline nature (with electro-positive charge) has a stronger adhesion with the weakly acidic bitumen than an acidic mineral [43-44]. 
Table 3 The adhesion property between minerals and bitumen at dry and wet conditions.

\begin{tabular}{|c|c|c|c|c|}
\hline Models & $\begin{array}{r}\Delta \boldsymbol{E}_{\text {MB-dry }} \\
(\mathrm{kcal} / \mathrm{mol})\end{array}$ & $\begin{array}{r}W_{M B-d r y} \\
\left(\mathrm{~mJ} / \mathrm{m}^{2}\right)\end{array}$ & $\begin{array}{r}\Delta \boldsymbol{E}_{\text {MB-wet }} \\
\text { (kcal/mol) }\end{array}$ & $\begin{array}{l}W_{\text {MB-wet }} \\
\left(\mathrm{mJ} / \mathrm{m}^{2}\right)\end{array}$ \\
\hline Quartz-bitumen & 230.29 & 42.87 & 40.58 & 7.56 \\
\hline Calcite-bitumen & 250.54 & 57.13 & 41.07 & 9.36 \\
\hline Albite-bitumen & 6361.98 & 1257.25 & 5234.93 & 1033.88 \\
\hline $\begin{array}{l}\text { Microcline- } \\
\text { bitumen }\end{array}$ & 16520.00 & 3241.55 & 16346.78 & 3206.41 \\
\hline
\end{tabular}

Fig. 5 shows the energy components that contribute to the work of adhesion ( $W_{\text {MB-dry }}$ ) between mineral and bitumen at the dry condition. It can be found that the total energy equals to the nonbond energy for the four mineral-bitumen systems (note that based on Eq. (1), the total energy = covalent energy + non-bond energy which includes van der Waals and electrostatic energy). This indicates that the adhesion between minerals and bitumen completely results from the nonbond interaction. The covalent interaction contributes little or nothing to the mineral-bitumen adhesion bond, indicating that no chemical bond is formed between minerals and bitumen. Within the non-bond energy components, the van der Waals interaction contributes to the main adhesion between quartz and bitumen. This is reasonable since the quartz is an electronically neutral mineral, having a very weak or none electrostatic interaction with other materials. However, the electrostatic interaction becomes the major contribution for the adhesion between the bitumen and those alkali minerals (i.e., calcite, albite and microcline), as demonstrated in Fig.5. This finding is consistent with the previous study, in which Mirzababaei [45] has reported that calcareous aggregates that have a high amount of calcite show a strong electrostatic adhesion with bitumen. In sum, the adhesion between minerals and bitumen is attributed to non-bond interaction energy, where the major contribution results from van der Waals interaction for the neutral minerals like quartz and from the electrostatic interaction for the alkali minerals such as calcite, albite and microcline.

Under the wet condition, the work of adhesion ( $W_{\text {MB-wet }}$ ) between mineral and bitumen is also calculated, as shown in Table 3. The work of adhesion ( $W_{\text {MB-wet }}$ ) of the quartz-bitumen bond is $7.56 \mathrm{~mJ} / \mathrm{m}^{2}$, while the work of adhesion ( $W_{\text {MB-wet }}$ ) of the calcite-bitumen bond is $9.36 \mathrm{~mJ} / \mathrm{m}^{2}$. It is concluded that calcite-bitumen bond is still stronger than the quartz-bitumen bond even in the presence of water. This is in agreement with the previous study from $\mathrm{Lu}$ and Wang [46] who found that calcite was more prone to adsorb bitumen than quartz at the wet condition. The microcline-bitumen model has the largest work of adhesion ( $W_{\text {MB-wet }}$ ) of $3206.41 \mathrm{~mJ} / \mathrm{m}^{2}$ and the work of adhesion ( $W_{\text {MB-wet }}$ ) of the albite-bitumen model is $1033.88 \mathrm{~mJ} / \mathrm{m}^{2}$. The ranking for the 
adhesion between the four minerals and bitumen at wet condition remains unchanged from that at the dry condition, which is: microcline $>$ albite $>$ calcite $>$ quartz. However, it can be found that the moisture reduces the adhesion between minerals and bitumen and the decrease of the work of adhesion between minerals and bitumen from dry to the wet condition is different depending on the mineral types.

To quantify the susceptibility of the mineral-bitumen adhesion to the presence of water, adhesion degradation percentage $\left(\mathrm{R}_{\mathrm{AD}}\right)$ from dry to wet conditions is proposed using the work of adhesion. In this study, the degradation ratio $\left(\mathrm{R}_{\mathrm{AD}}\right)$ is calculated as the difference of the work of adhesion for the mineral-bitumen model at dry and wet conditions divided by the work of adhesion at the dry condition, as shown in Eq. (6). A higher value of $\left(\mathrm{R}_{\mathrm{AD}}\right)$ means a greater degradation of the mineral-bitumen adhesion and indicates a higher susceptibility of the mineral-bitumen interface to water.

$$
\mathrm{R}_{\mathrm{AD}}=\left(W_{\mathrm{MB}-\mathrm{dry}}-W_{\mathrm{MB}-\mathrm{wet}}\right) / W_{\mathrm{MB}-\mathrm{dry}}
$$

where $W_{\text {MB-dry }}$ is the work of adhesion between mineral and bitumen at the dry condition, and $W_{\text {MB-wet }}$ is the work of adhesion between mineral and bitumen at the wet condition.

Fig. 6 shows the adhesion degradation ratio $\left(\mathrm{R}_{\mathrm{AD}}\right)$ for the four interface models. The quartzbitumen model has a $\mathrm{R}_{\mathrm{AD}}$ value of $82 \%$, which is very close to that of the calcite-bitumen model (84\%). However, the $\mathrm{R}_{\mathrm{AD}}$ values for the albite-bitumen and microcline-bitumen models are $18 \%$ and $1 \%$, respectively, which are much smaller than those of the quartz-bitumen and calcitebitumen models. This is due to the fact that the highly alkali minerals such as microcline and albite induce very high and stable electrostatic interactions with bitumen as shown in Fig. 5, which can little be reduced by the presence of water. This result proves that the susceptibility of the adhesion to moisture depends on the mineral types and highly alkali minerals provide a stronger adhesion stability and less moisture susceptibility than weak alkali or neutral minerals.

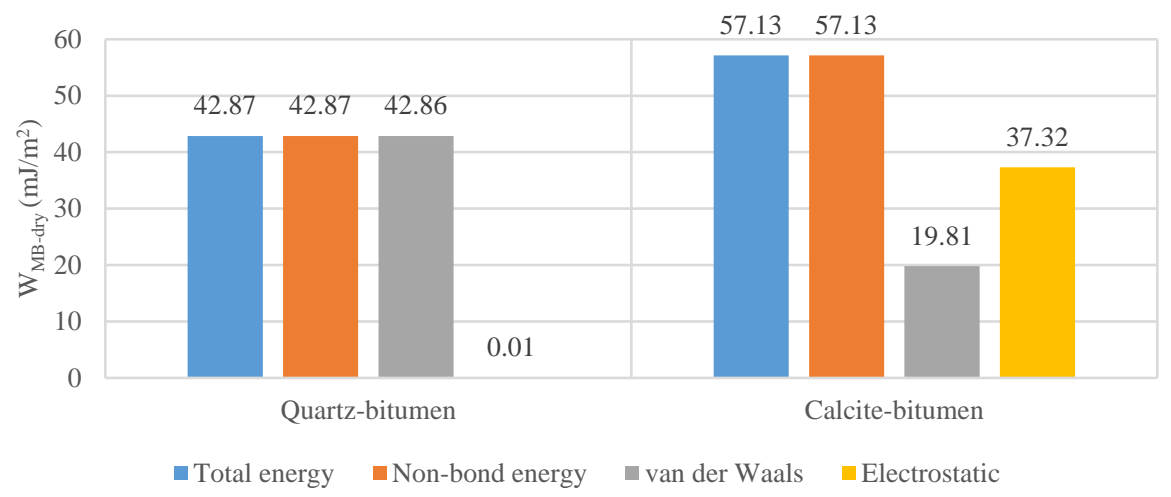


Gao, et al.

(a) Quartz-bitumen model and calcite-bitumen model

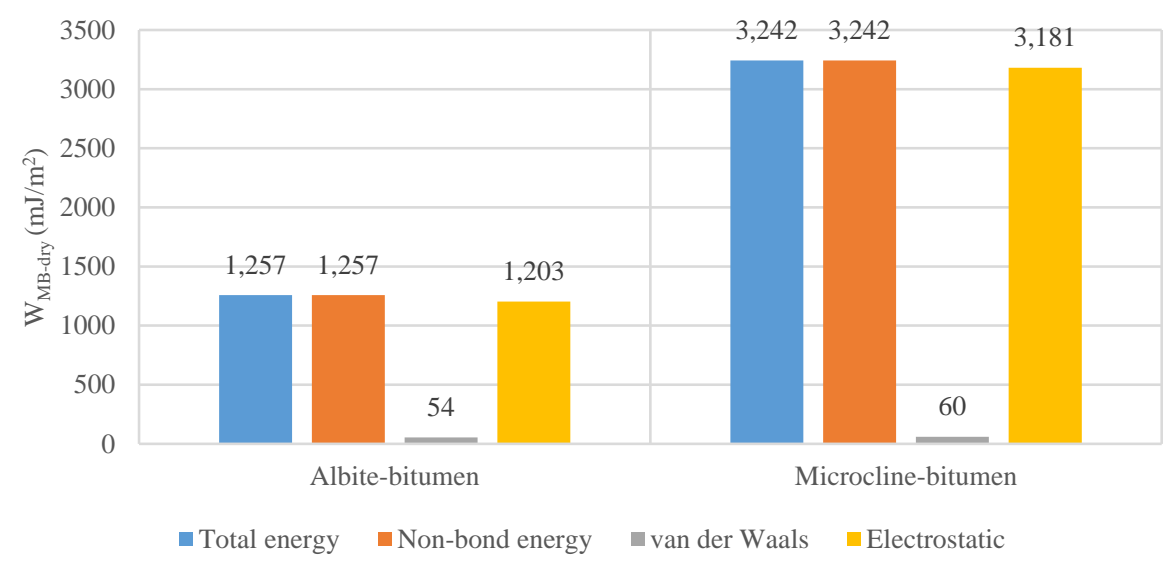

(b) Albite-bitumen model and microcline-bitumen model

Fig. 5. Contribution of non-bond components including van der Waals and electrostatic energy to the total work of adhesion ( $W_{\text {MB-dry }}$ ) for different mineral-bitumen systems.

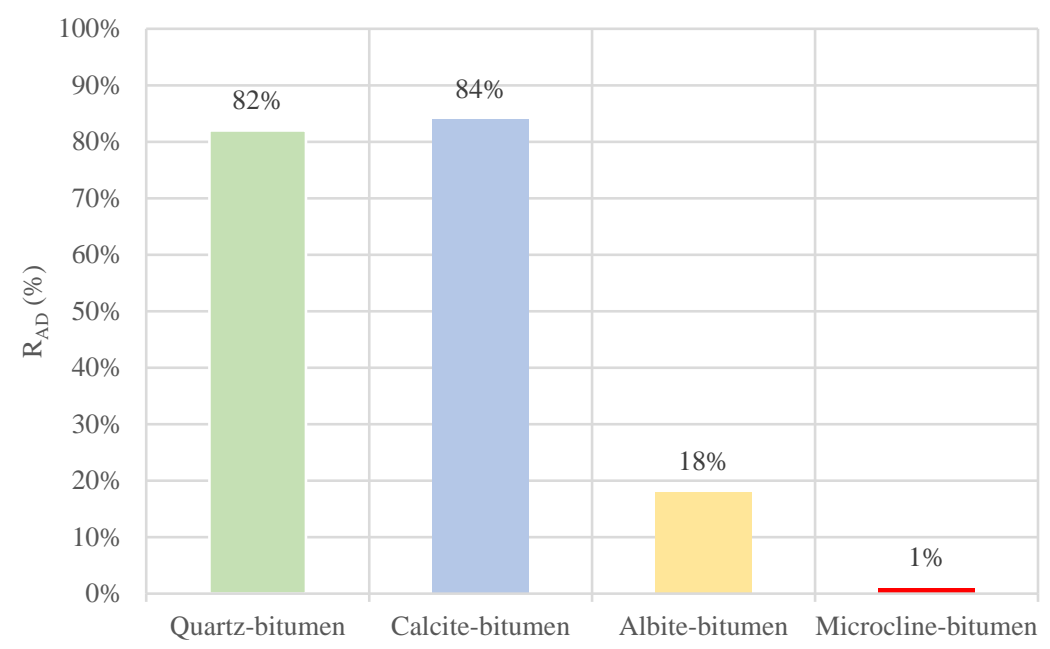

Fig. 6. The adhesion degradation ratio $\left(\mathrm{R}_{\mathrm{AD}}\right)$ for the four mineral-bitumen systems.

\subsection{Work of debonding during stripping process}

Due to the water-loving nature of mineral and the hydrophobic nature of bitumen, water tends to separate the mineral-bitumen interface and thus has a detrimental influence on the bonding between mineral and bitumen. Therefore, it is extremely important to investigate how water, mineral and bitumen interact at their interface, and how water causes the debonding between mineral and bitumen, namely the stripping or moisture damage in asphalt concrete.

Fig. 7 shows a process how water causes the debonding between mineral and bitumen [33]. 
This process can be decomposed as two steps: 1) debonding occurs on the mineral-bitumen interface, and 2) water bonds with mineral and bitumen, respectively, and forms a watermineral interface and a water-bitumen interface. The work of debonding $\left(W_{\mathrm{MBW}}\right)$, defined as the work required to displace bitumen by water on the mineral-bitumen interface, is expressed by Eq. (7).

$$
W_{\mathrm{MBW}}=\left(\Delta E_{\mathrm{MB}-\mathrm{dry}}-\Delta E_{\mathrm{MW}}-\Delta E_{\mathrm{BW}}\right) / A
$$

where $W_{\mathrm{MBW}}$ is the work of debonding in the process of water diffusing into the mineralbitumen interface; $\Delta E_{\mathrm{MB} \text {-dry }}$ is the interaction energy between mineral and bitumen with no presence of water (at dry condition); $\Delta E_{\mathrm{MW}}$ is the interaction energy between mineral and water with no presence of bitumen; $\Delta E_{\mathrm{BW}}$ is the interaction energy between bitumen and water with no presence of mineral; and $A$ is the interface area where the debonding occurs. Based on the definition of the work of debonding ( $W_{\mathrm{MBW}}$ ) in Eq. (7), a positive value of $W_{\mathrm{MBW}}$ indicates that the mineral-bitumen interface system needs to absorb energy from the external sources to displace the bitumen by water (i.e., debonding or stripping). A negative value of $W_{\mathrm{MBW}}$ means that energy is released during the displacement and the debonding will be occurring spontaneously and naturally without a need of the external energy. Physically the work of debonding $\left(W_{\mathrm{MBw}}\right)$ describes how difficult the water can penetrate into the mineral-bitumen interface or how likely the debonding will be occurring. A higher magnitude of $W_{\mathrm{MBW}}$ indicates that more energy is absorbed (positive $W_{\mathrm{MBW}}$ ) or released (negative $W_{\mathrm{MBW}}$ ) when water diffuses into the interface, thus the interface debonding is less likely to occur and the interfacial adhesion has a good resistance to water damage [46]. Note that the work of debonding ( $\left.W_{\mathrm{MBW}}\right)$ determines the potential of the bitumen-mineral interface to resist the moisture damage during a stripping process rather than the bonding strength between the bitumen and minerals which should be quantified by the work of adhesion at dry or wet conditions.
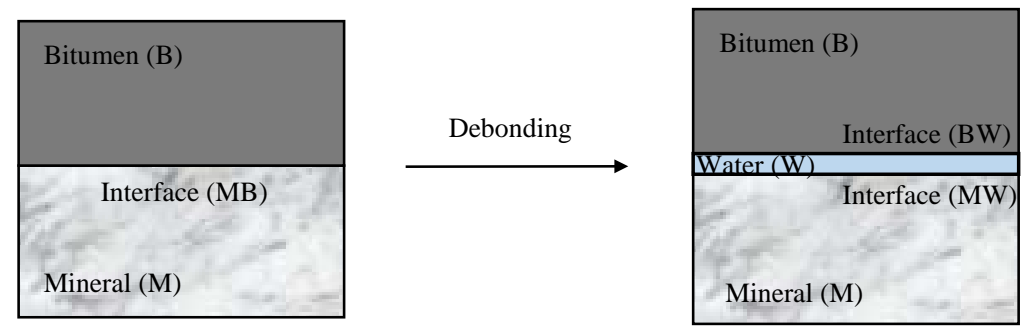

Fig. 7. Displacement of bitumen from the mineral-bitumen interface by water.

Table 4 shows that the work of debonding ( $W_{\mathrm{MBW}}$ ) for the four mineral-bitumen systems are all negative, which means that the debonding will be occurring spontaneously and naturally between bitumen and the four minerals. This finding is consistent with the laboratory 
measurements finding that the total work done in the stripping process was less than zero (i.e., energy is released) for almost all bitumen-aggregate systems [33]. The results indicate that the mineral-bitumen systems during the debonding process do not need to absorb the external energy and stripping will occur spontaneously in the field for the four minerals when water exists. Fundamentally this is interpreted as that the mineral-bitumen debonding process is thermodynamically favourable and the debonding is a process of lowering the total potential energy of the system.

Table 4 shows that the quartz-bitumen model has a $W_{\text {MBW }}$ value of $-0.37 \mathrm{~mJ} / \mathrm{m}^{2}$, whereas the $W_{\text {MBW }}$ value of the calcite-bitumen model is $-2871.04 \mathrm{~mJ} / \mathrm{m}^{2}$. The magnitude of $W_{\mathrm{MBW}}$ for the calcite-bitumen model is much larger than that of the quartz-bitumen model, which indicates that calcite has a better resistance to stripping than quartz. This agrees with the previous findings from experiments [33] or simulations [46] that limestone had better anti-moisture damage property than granite. The $W_{\mathrm{MBW}}$ values for the albite-bitumen and microcline-bitumen models are -3074.86 and $-7187.55 \mathrm{~mJ} / \mathrm{m}^{2}$, respectively. The ranking of the resistance to moisture damage for the four minerals is as follows: microcline $>$ albite $>$ calcite $>$ quartz. During the interface debonding, the alkaline minerals calcite, albite and microcline have stronger bonds with the acidic bitumen due to their strong electrostatic interactions, while quartz with an acidic nature has a very weak adhesion with bitumen which results only from the van der Waals interaction. Thus, the minerals calcite, albite and microcline have better resistance to moisture stripping than quartz. This result indicates that the resistance to wet stripping of the mineral-bitumen interface is strongly dependent on the chemistry of the mineral surface.

Table 4 The work of debonding for four mineral-bitumen models.

\begin{tabular}{|c|c|c|c|c|}
\hline Models & $\begin{array}{r}\Delta E_{\text {MB-dry }} \\
\text { (kcal/mol) }\end{array}$ & $\begin{array}{r}\Delta \boldsymbol{E}_{\mathrm{MW}} \\
(\mathbf{k c a l} / \mathrm{mol})\end{array}$ & $\begin{array}{r}\Delta E_{\mathrm{BW}} \\
(\mathrm{kcal} / \mathrm{mol})\end{array}$ & $\begin{array}{r}W_{\text {MBW }} \\
\left(\mathrm{mJ} / \mathrm{m}^{2}\right)\end{array}$ \\
\hline Quartz-bitumen & 230.29 & 117.79 & 114.47 & -0.37 \\
\hline Calcite-bitumen & 250.54 & 12752.15 & 89.66 & -2871.04 \\
\hline Albite-bitumen & 6361.98 & 21885.39 & 36.16 & -3074.86 \\
\hline $\begin{array}{l}\text { Microcline- } \\
\text { bitumen }\end{array}$ & 16520.00 & 53056.87 & 93.18 & -7187.55 \\
\hline
\end{tabular}

Through investigating the work of adhesion and the work of debonding for the mineral-bitumen interface, the bitumen-mineral interface stripping mechanism can be analysed at the atomistic scale. Since the work of debonding is all negative, the debonding always occurs for the four minerals with bitumen when water exists. During the debonding, water diffuses into the interface between the minerals and bitumen. However, residual adhesion still exists between 
the aggregate minerals and the bitumen even though water has been diffused throughout the interface, which is quantified by the work of adhesion at wet condition. For the acidic or weak alkali minerals, such as quartz or calcite, their adhesion with bitumen at wet condition is so low which can be easily exceeded by the external loadings such as traffic loading or thermal loading. When this occurs, the stripping will be happening in the asphalt mixtures.

\section{Conclusions}

In this study, the effects of aggregate minerals and water on adhesion property and debonding behaviour of the bitumen-mineral interface were investigated using molecular dynamics (MD) simulation. Four representative minerals (quartz, calcite, albite, and microcline) were selected to build the interface models, and the molecular interactions between minerals and bitumen were quantified through MD simulations. The work of adhesion was defined to characterise the adhesion strength of the bitumen-mineral interface at dry and wet conditions. The work of debonding was used to quantify the difficulty of a stripping process when water diffuse into the interface between minerals and bitumen. The main findings from this study are as follows:

(1) For both dry and wet conditions, the calcite-bitumen bond is stronger than the quartzbitumen bond, and the adhesion of the four minerals with bitumen is ranked as: microcline $>$ albite $>$ calcite $>$ quartz. However, the moisture can reduce the adhesion between minerals and bitumen by $82 \%, 84 \%, 18 \%$ and $1 \%$ for the quartz, calcite, albite and microcline, respectively.

(2) The calcite has a better resistance to wet stripping than quartz. The ranking of the resistance to water damage for the four minerals is microcline $>$ albite $>$ calcite $>$ quartz. The resistance to wet stripping of the mineral-bitumen interface is strongly dependent on the chemistry of the mineral surface.

(3) The adhesion between minerals and bitumen is attributed to non-bond interaction energy, where the major contribution is from van der Waals interaction for the neutral minerals like quartz and from the electrostatic interaction for the alkali minerals such as calcite, albite and microcline.

(4) The mineral-bitumen debonding process is spontaneous when water exists, which proves that stripping is thermodynamically favourable and the debonding is a process of lowering the total potential energy of the bitumen-mineral system. Through investigating the work of adhesion and the work of debonding for the mineral-bitumen interface, the wet interface stripping mechanism can be analysed at the atomistic scale. 
This study explained the stripping mechanism of asphalt mixtures from the perspective of molecular interactions. The molecular dynamics simulation was proved to be able to effectively investigate the adhesion and debonding of the mineral-bitumen interface at the nanoscale. However, only pure minerals were studied in this paper. Future study should evaluate the effects of aggregates composed of different minerals on the adhesion property and debonding behaviours between bitumen and aggregate.

\section{Acknowledgement}

The authors acknowledge the financial support provided by Aston University via a $\mathrm{PhD}$ studentship and by European Union’s Horizon 2020 programme via a Marie S. Curie Individual Fellowship project (Grant No. 749232 - AMAM).

\section{Reference}

[1] Y. Zhang, R. Luo, R.L. Lytton, Mechanistic modeling of fracture in asphalt mixtures under compressive loading, Journal of Materials in Civil Engineering 25(9) (2013) 1189-1197.

[2] R. L. Lytton, Y. Zhang, F. Gu, X. Luo, Characteristics of damaged asphalt mixtures in tension and compression. International Journal of Pavement Engineering, 19(3), (2018).292-306.

[3] Y. Zhang, X. Luo, R. Luo, R.L. Lytton, Crack initiation in asphalt mixtures under external compressive loads, Construction and Building Materials 72 (2014) 94-103.

[4] Y. Zhang, F. Gu, B. Birgisson, R.L. Lytton, Modelling cracking damage of asphalt mixtures under compressive monotonic and repeated loads using pseudo J-integral Paris’ law, Road Materials and Pavement Design (2017) DOI:10.1080/14680629.2018.1418706

[5] Y. Gao, M. Dong, L. Li, L. Wang, Z. Sun, Interface effects on the creep characteristics of asphalt concrete, Construction and Building Materials 96 (2015) 591-598.

[6] M. Dong, Y. Gao, L. Li, L. Wang, Z. Sun, Viscoelastic micromechanical model for dynamic modulus prediction of asphalt concrete with interface effects, Journal of Central South University 23 (2016) 926-933.

[7] R.L. Lytton, E.A. Masad, C. Zollinger, R. Bulut, D.N. Little, Measurements of surface energy and its relationship to moisture damage (No. FHWA/TX-05/0-4524-2), 2005.

[8] M.J. Khattak, G.Y. Baladi, L.T. Drzal, Low temperature binder-aggregate adhesion and mechanistic characteristics of polymer modified asphalt mixtures, Journal of Materials in Civil Engineering 19 (5) (2007) 411-422.

[9] F. Canestrari, F. Cardone, A. Graziani, F.A. Santagata, H.U. Bahia, Adhesive and cohesive properties of asphalt-aggregate systems subjected to moisture damage, Road Materials and Pavement Design 11 (1) (2010) 11-32.

[10] R. Moraes, R. Velasquez, H. Bahia, Measuring the effect of moisture on asphalt-aggregate bond with the bitumen bond strength test, Transportation Research Record No. 2209 (2011) 70-81.

[11] E. Fini, I. Al-Qadi, Development of a pressurized blister test for interface characterization of aggregate highly polymerized bituminous materials, Journal of Materials in Civil Engineering ASCE 
Gao, et al.

23 (5) (2011) 656-663.

[12] H.R. Fischer, E.C. Dillingh, C.G.M. Hermse, On the interfacial interaction between bituminous binders and mineral surfaces as present in asphalt mixtures, Applied Surface Science 265 (2013) 495-499.

[13] L. Zhang, M.L. Greenfield, Analyzing properties of model asphalts using molecular simulation, Energy \& Fuels 21 (2007) 1712-1716.

[14] L. Zhang, M.L. Greenfield, Relaxation time, diffusion, and viscosity analysis of model asphalt systems using molecular simulation, The Journal of Chemical Physics 127 (2007) 1-13.

[15] D.D. Li, M.L. Greenfield, Chemical compositions of improved model asphalt systems for molecular simulations, Fuel 115 (2014) 347-356.

[16] D.D. Li, M.L. Greenfield, Viscosity, relaxation time, and dynamics within a model asphalt of larger molecules, The Journal of Chemical Physics 140 (2014) 1-11.

[17] Y. Lu, L.B. Wang, Nanoscale modelling of mechanical properties of asphalt-aggregate interface under tensile loading, International Journal of Pavement Engineering 11 (2010) 393-401.

[18] Y. Lu, L.B. Wang, Nano-mechanics modelling of deformation and failure behaviours at asphaltaggregate interfaces, International Journal of Pavement Engineering 12(4) (2011) 311-323.

[19] H. Wang, E. Lin, G.J. Xu, Molecular dynamics simulation of asphalt-aggregate interface adhesion strength with moisture effect, International Journal of Pavement Engineering 18(5) (2015) 414-423.

[20] G.J. Xu, H. Wang, Molecular dynamics study of interfacial mechanical behavior between asphalt binder and mineral aggregate, Construction and Building Materials 121 (2016) 246-254.

[21] R.A. Tarefder, I. Arisa, Molecular dynamic simulations for determining change in thermodynamic properties of asphaltene and resin because of aging, Energy Fuels 25 (2011) 2211-2222.

[22] J.L. Pan, R.A. Tarefder, Investigation of asphalt aging behavior due to the oxidation using molecular dynamics simulation, Molecular Simulation 42(8) (2016) 667-678.

[23] G.J. Xu, H. Wang, Molecular dynamics study of oxidative aging effect on asphalt binder properties, Fuel 188 (2017) 1-10.

[24] Y.J. Ding, B.S. Huang, X. Shu, Y.Z. Zhang, M.E. Woods, Use of molecular dynamics to investigate diffusion between virgin and aged asphalt binders, Fuel 174 (2016) 267-273.

[25] A. Bhasin, R. Bommavaram, M.L. Greenfield, D. Little, Use of molecular dynamics to investigate self-healing mechanisms in asphalt binders, Journal of Materials in Civil Engineering 23 (4) (2011) 485-492.

[26] D.Q Sun, T.B Lin, X.Y Zhu, Y. Tian, F.L. Liu, Indices for self-healing performance assessments based on molecular dynamics simulation of asphalt binders, Computational Materials Science 114 (2016) 86-93.

[27] Y. Hou, L.B. Wang, D.W. Wang, M. Guo, P. Liu, J.X. Yu, Characterization of bitumen micromechanical behaviors using AFM, Phase Dynamics Theory and MD Simulation, Materials 2017, 10, 208; doi:10.3390/ma10020208

[28] Y. Hou, L.B. Wang, D.W. Wang, X. Qu, J.F. Wu, Using a molecular dynamics simulation to investigate asphalt nano-cracking under external loading conditions, Applied Sciences 2017, 7, 770; doi:10.3390/app7080770 
[29] A.L. Lyne, P. Redelius, M. Collin, B. Birgisson, Characterization of stripping properties of stone material in asphalt, Materials and Structures 46 (2013) 47-61.

[30] M. Horgnies, E. Darque-Ceretti, H. Fezai, E. Felder, Influence of the interfacial composition on the adhesion between aggregates and bitumen: Investigations by EDX, XPS and peel tests, International Journal of Adhesion \& Adhesives 31 (2011) 238-247.

[31]E.H. Nickel, Definition of a mineral. Can Mineral 33(3) (1995) 689-690.

[32] S. Pople, M. Williams, Science to GCSE, 2nd edn, Oxford University Press, Oxford, 2002.

[33]D. Little, A. Bhasin, Using surface energy measurements to select materials for asphalt pavement, in: Final Report for NCHRP Project 9-37, 2006.

[34] D.C. Rapaport, The art of molecular dynamics simulation, Cambridge: Cambridge University Press, 1997.

[35]Z.J. Dong, Z.Y. Liu, P. Wang, X.B. Gong, Nanostructure characterization of asphalt-aggregate interface through molecular dynamics simulation and atomic force microscopy, Fuel 189 (2017) 155-163.

[36] H. Sun, COMPASS: an ab initio force-field optimized for condensed-phase applications-overview with details on alkane and benzene compounds, The Journal of Physical Chemistry B 102 (1998) 7338-7364.

[37] Materials Studio, Biovia Inc.: San Diego, CA; 2013.

[38] D.R. Jones, SHRP materials reference library, asphalt cements: a concise data compilation, SHRPA-645, Strategic Highway Research Program National Research Council, Washington, DC; 1993.

[39] N. Kringos, T. Scarpas, C. Kasbergen, P. Selvadurai, Modelling of combined physical-mechanical moisture-induced damage in asphaltic mixes, Part 1: governing processes and formulations, International Journal of Pavement Engineering 9 (2) (2008a) 115-128.

[40] N. Kringos, A. Scarpas, A. Copeland, J. Youtcheff, Modelling of combined physical-mechanical moisture-induced damage in asphaltic mixes, Part 2: moisture susceptibility parameters, International Journal of Pavement Engineering 9 (2) (2008b) 129-151.

[41] G.J. Xu, H. Wang, Study of cohesion and adhesion properties of asphalt concrete with molecular dynamics simulation, Computational Materials Science 112 (2016) 161-169.

[42] Y.P. Yin, H.X. Chen, D.L. Kuang, L.F. Song, L. Wang, Effect of chemical composition of aggregate on interfacial adhesion property between aggregate and asphalt, Construction and Building Materials 146 (2017) 231-237.

[43]Z.W. Chen, J. Xie, Y. Xiao, J.Y. Chen, S.P. Wu, Characteristics of bonding behavior between basic oxygen furnace slag and asphalt binder, Construction and Building Materials 64 (2014) 60-66.

[44] S. Abo-Qudais, H. Al-Shweily, Effect of aggregate properties on asphalt mixtures stripping and creep behaviour, Construction and Building Materials 21 (2007) 1886-1898.

[45] P. Mirzababaei, Effect of zycotherm on moisture susceptibility of Warm Mix Asphalt mixtures prepared with different aggregate types and gradations, Construction and Building Materials 116 (2016) 403-412.

[46] Y. Lu, L.B. Wang, Atomistic modelling of moisture sensitivity: a damage mechanisms study of asphalt concrete interfaces, Road Materials and Pavement Design 18:sup3 (2017) 200-214. 